\title{
The Impact of Out-of-Pocket Health Expenditure on Maternal Health: Empirical Evidence from Central and Latin American Countries
}

\author{
Achille Dargaud Fofack, M.Sc., Steve Sarpong, M.Sc. \\ Business Administration Department, Cyprus International University, 99258 Lefkoşa, via Mersin 10, 99258 Turkey. \\ Received 6 December 2018 • Revised 30 April 2019 • Accepted 30 April 2019 • Published online 25 June 2019
}

\section{Abstract:}

Objective: The aim of this paper is to assess the impact of out-of-pocket (OOP) health expenditure on maternal health outcomes using a panel of twenty Central and Latin American countries between 2000 and 2015.

Material and Methods: Six different estimation techniques were used in the analysis in order to check the robustness of the findings. Those estimation techniques were: the ordinary least squares method, the Prais-Winsten correlated panels corrected standard errors regression, the fixed and the random effects models, the generalized least squares method and the bias-corrected least squares dummy variable method.

Results: After controlling for female education, gross domestic product and remittances, it was found that a surge in (OOP) health expenditure significantly deteriorates maternal health as it leads to a decrease in skilled birth attendance and an increase in maternal mortality. It was also found that in Central and Latin American countries, educated women tended to be healthier, and maternal health care was mainly financed with the money received from friends and family members living abroad.

Conclusion: It is therefore recommended that public health authorities design and implement protective health care financing programs, such as health insurance.

Keywords: Central America, Latin America, maternal mortality, out-of-pocket expenditure, skilled birth attendance

Contact: Achille Dargaud Fofack, M.Sc.

Business Administration Department, Cyprus International University, 99258

Lefkoşa, via Mersin 10, 99258 Turkey.

Email: adfofack.irlaem@gmail.com/afofack@ciu.edu.tr
J Health Sci Med Res 2019;37(3):237-245 doi: 10.31584 /jhsmr.201957 www.jhsmr.org 


\section{Introduction}

Health systems in developing countries are impaired by inefficiency, inequitable access, inadequate funding and a poor quality of services. More than 150 million people often experience financial problems arising from unexpected out-of-pocket (OOP) health expenditures when seeking healthcare services. ${ }^{1}$ Mclyntyre et al. ${ }^{2}$ analyzed the economic consequences of illness and payments for health care at the household level in low and middle-income countries and found that poor households were often exposed to OOP expenditures and related indirect costs. Substantial OOP health expenditure can push middle-income households into poverty and compel low-income households into even deeper poverty, particularly when it is associated with lost household income due to illness. These expenditures tend to be catastrophic for households with limited financial means as they exceed $10.0 \%$ of their income. Catastrophic OOP expenditures could be found in all areas of healthcare services, but the magnitude seems to be more pronounced when it comes to maternal health.

A growing literature provides evidence that in developing countries the impact of OOP expenditure on maternal health is often catastrophic for rural folks, the less educated, slum dwellers and poor households. People living below the poverty line find it difficult to devote a chunk of their income to health care. Indeed, poor households often cope with medical expenses by selling assets or borrowing money. ${ }^{2-5}$ Such a pattern is found to be all the more relevant when a member of the household is hospitalized $^{6}$ or when health care is sought from private health facilities. ${ }^{7}$ In contrast to developed countries, healthcare services in Central and Latin American countries are largely financed by OOP expenditures. OOP payments as a percentage of current health expenditure vary across continents. The figure in Latin America and the Caribbean was higher than the global average, but lower than that in low and middle-income countries (Figure 1).

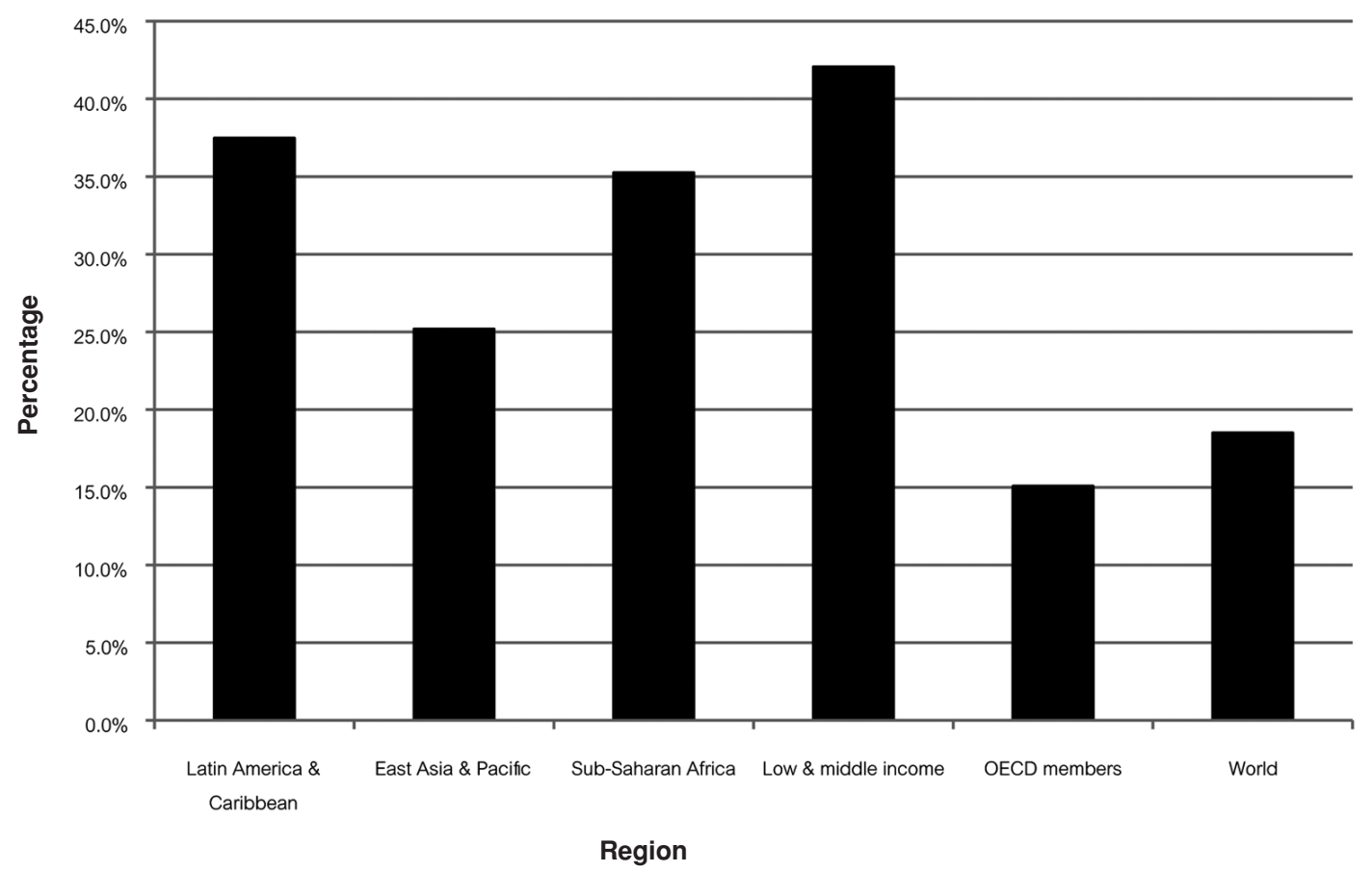

Figure 1 Out-of-pocket healthcare expenditure as a percentage of current healthcare expenditure (average over 20002015) 
A study in Vietnam examining the catastrophic and poverty impacts of OOP health expenditure from 20022010 in households nationwide revealed that more elderly people, more children under 6 years old, and more members in the household were significantly associated with catastrophic OOP expenditures. In contrast, urban households and households with health insurance were significantly associated with less catastrophic OOP expenditures. ${ }^{8}$ In addition, a study in Chile found that household income level, type of health insurance, use of health care and the recurrence of diseases determine OOP expenditure for people with chronic non-communicable diseases. ${ }^{9}$ Both studies used a simple regression for analysis, which may not have been sufficiently robust. Integrating six different estimation techniques, namely the ordinary least squares, the Prais-Winsten correlated panels corrected standard errors, the fixed-effect model, the random-effect model, the generalized least squares and the bias-corrected least squares dummy variable methods is useful for checking the robustness of the findings. The aims of this analysis were to assess the evolution of maternal health from 2000-2015 in Central and Latin American countries and measure the impact of OOP expenditure on maternal health.

\section{Material and Methods}

A secondary analysis using data obtained from the World Bank (World Development Indicators) between 2000 and 2015 was conducted. Twenty Central and Latin American countries were selected based on data availability. These countries were Argentina, Belize, Bolivia, Brazil, Chile, Columbia, Costa Rica, Ecuador, El Salvador, Guatemala, Guyana, Honduras, Mexico, Nicaragua, Panama, Paraguay, Peru, Suriname, Uruguay, and Venezuela.

OOP expenditure is expressed as a percentage of total healthcare expenditure and both births attended by skilled healthcare staff and the maternal mortality ratio account for maternal health. The former is expressed as a percentage of total births while the latter is expressed per 100,000 live births.

Three control variables are included in the analysis because it is assumed that they mediate the relation between OOP expenditure and maternal health. The first control variable (the growth rate of the gross domestic product (GDP) per capita) accounts for the average domestic income. It is assumed that people with high incomes can afford medical expenses and improve their health status. The second variable (personal remittances received, expressed as percentage of GDP) accounts for the income received from family and friends living abroad. This variable is included in the analysis because Central and Latin Americans heavily rely on remittances to support their living standards. ${ }^{10}$ As for the third control variable (female literacy rate), it accounts for education and it is assumed that a woman's level of education positively influences her health status.

The general specification of the econometric model used in the analysis is given by the following equation:

$$
H O_{i t}=\alpha_{0}+\alpha_{1} 00 P_{i t}+\alpha_{2} G D P_{i t}+\alpha_{3} \text { Remittances }_{i t}+
$$
$\alpha_{4}$ Fem_Literacy $_{i t}+\varepsilon_{i t}$

Where $\mathrm{HO}_{\text {it }}$ stands for maternal health outcome (maternal mortality ratio and births attended by skilled health staff) for country $\mathrm{i}$ and period $\mathrm{t}$; $00 \mathrm{P}_{\text {it }}$ stands for OOP healthcare expenditure; $G D P_{i t}$ stands for the growth rate of GDP per capita; Remittances ${ }_{i t}$ stands for personal remittances received; Fem_Literacy ${ }_{i t}$ stands for the adult female literacy rate; $\varepsilon_{i t}$ is the error term; and $\alpha_{i}$ (with $i=$ $0,1,2,3,4)$ are the coefficients to be estimated.

Six different estimation techniques are used in the analysis in order to check the robustness of the findings. Firstly, the model described in equation (1) is estimated using the ordinary least squares (OLS) method with 
country dummy variables. Secondly, the model is estimated using the Prais-Winsten correlated panels corrected standard errors (PCSE) regression with country dummy variables. Compared to the OLS method, this estimation technique allows us to compute robust standard errors and we added panel-specific first order autoregressive terms $(A R(1))$ to address serial correlations. In the next step, both the fixed and the random effects models are estimated to take into consideration alternative crosssectional effects. Then, with the help of the GLS method with country dummy variables, issues related to heteroskedasticity and autocorrelation (using panelspecific $A R(1)$ terms) are also addressed. Finally, a dynamic version of equation (1) is estimated using the bias-corrected least squares dummy variable (BCLSDV) method developed by Bruno. ${ }^{11}$ The bias correction is initialized using the Anderson and Hsiao 12 consistent estimator; the accuracy of the approximation is set $\theta\left(\frac{1}{N T^{2}}\right)$ to and standard errors are bootstrapped using 100 replicates.

\section{Results}

Maternal health in Central and Latin America Percentage of births by skilled birth attendants was high in all Central and Latin American countries included in this analysis (Figure 2). Between 2000 and 2015 about 88.0\% of births in the region were attended by skilled health staff on average. Trends of births by skilled birth attendants were rising in most countries, even reaching $100.0 \%$ in some countries. Relatively low percentages were seen in Guatemala and Guyana compared to other countries.

Trends of maternal mortality ratio were downward in most Central and Latin American countries (Figure 3). Between 2000 and 2015, countries such as Colombia, Ecuador, Guatemala, and Peru managed to bring down the maternal mortality ratio to below the regional average of 104 deaths per 100,000 live births. Notwithstanding the fact that Guyana and Honduras were experiencing downward trends in the maternal mortality ratio, recent data show that they are still above the regional average.

\section{Impact of OOP expenditure on maternal health}

Impact of OOP expenditure on skilled birth attendance is presented in Table 1. OOP expenditure was negatively and significantly associated with skilled birth attendance. The corresponding coefficient varied but the sign and the significance of its effect were robust across estimation techniques. On average, a $10.0 \%$ increase in OOP expenditure led to a $1.2 \%$ decrease in skilled birth attendance. Remittances had a positive and significant effect on skilled birth attendance, which was robust across estimation techniques. On average, a $10.0 \%$ increase in remittances led to a $4.2 \%$ decrease in skilled birth attendance. Female literacy had a positive and significant impact on skilled birth attendance across estimation techniques. GDP did not have a significant impact on skilled birth attendance and the sign of this impact varied across estimation techniques.

Table 2 shows that OOP expenditure was positively and significantly associated with the maternal mortality ratio. The effect was robust in all model specifications except one (bias-corrected least squares dummy variable method), and on average a $10.0 \%$ increase in OOP expenditure led to a $2.9 \%$ increase in maternal mortality (2,900 deaths for every 100,000 births). The female literacy rate was negatively and significantly associated across estimation techniques. GDP and remittances were found to have an insignificant effect on the maternal mortality ratio even though the sign and magnitude of their respective effect were robust across model specifications. 

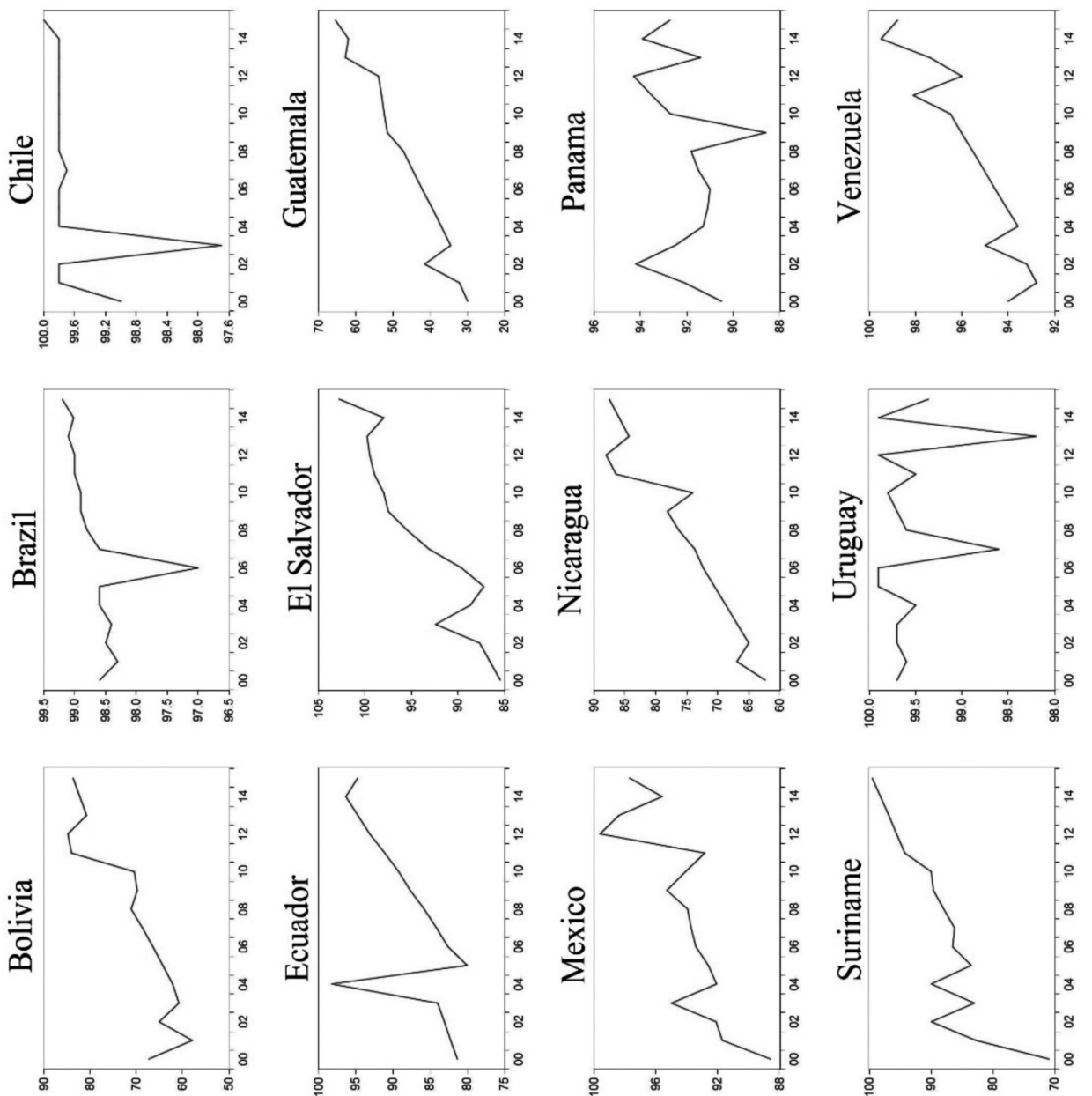

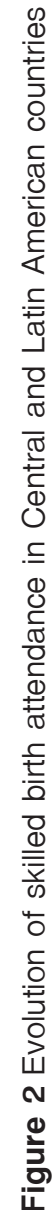
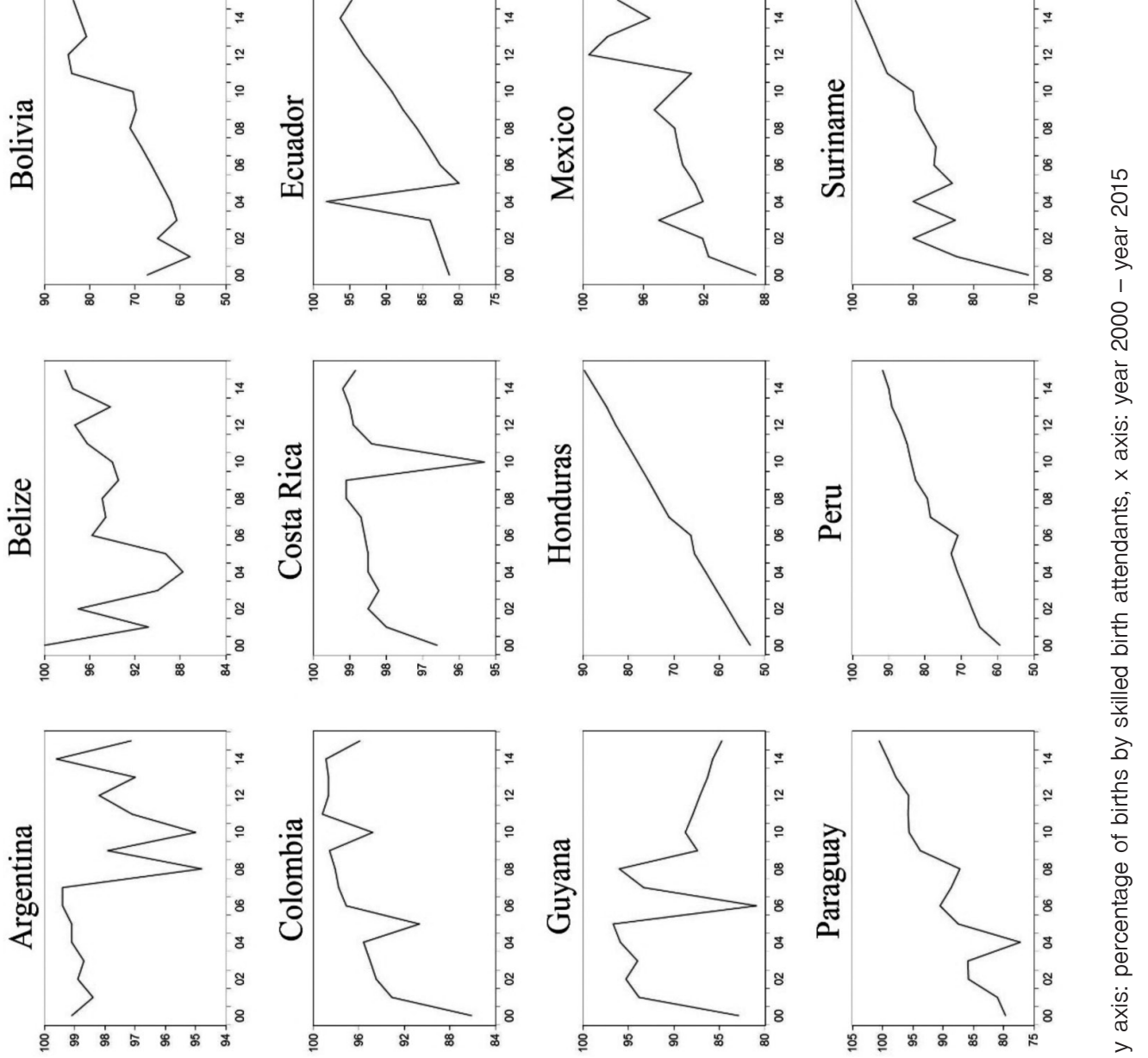

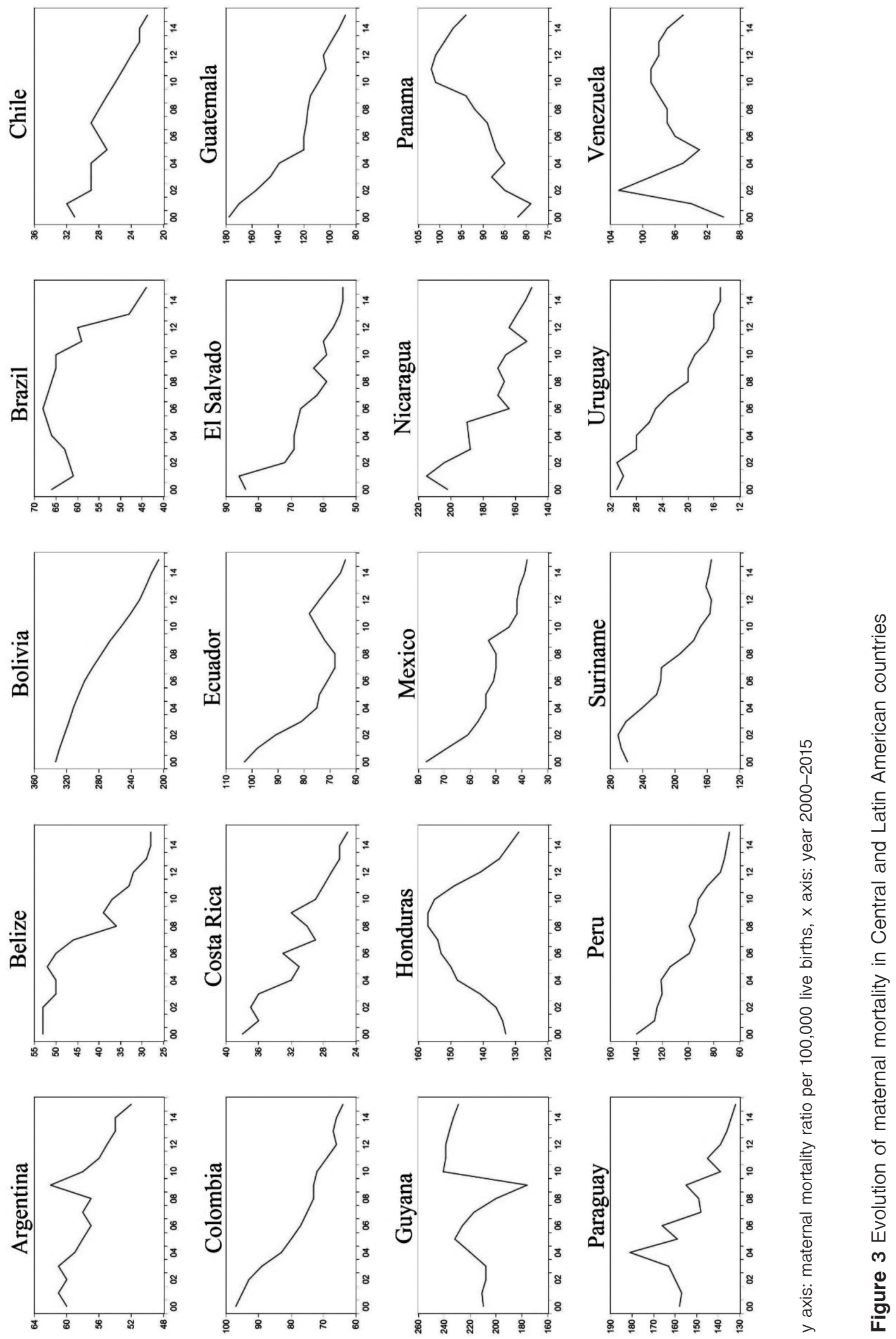
Table 1 Estimated impact of out-of-pocket expenditure on skilled birth attendance

\begin{tabular}{|c|c|c|c|c|c|c|}
\hline Variables & $\begin{array}{l}\text { Ordinary least } \\
\text { squares }\end{array}$ & $\begin{array}{l}\text { Prais-Winsten } \\
\text { regression }\end{array}$ & $\begin{array}{l}\text { Random effects } \\
\text { model }\end{array}$ & $\begin{array}{l}\text { Fixed effects } \\
\text { model }\end{array}$ & $\begin{array}{l}\text { Generalized } \\
\text { least squares }\end{array}$ & $\begin{array}{l}\text { Bias-corrected } \\
\text { least squares } \\
\text { dummy variable }\end{array}$ \\
\hline SBA & - & - & - & - & - & $0.735(0.049)^{\star * \star}$ \\
\hline OOP & $-0.161(0.048)^{\star \star \star}$ & $-0.111(0.056)^{\star *}$ & $-0.155(0.046)^{\star \star \star}$ & $-0.161(0.048)^{\star \star \star}$ & $-0.060(0.032)$ & $-0.091(0.039)^{\star *}$ \\
\hline GDP & $0.067(0.077)$ & $0.0147(0.050)$ & $0.064(0.077)$ & $0.067(0.077)$ & $-0.039(0.024)$ & $-0.011(0.062)$ \\
\hline Remittances & $0.562(0.135)^{\star * *}$ & $0.479(0.187)^{\star \star}$ & $0.502(0.123)^{\star \star \star}$ & $0.562(0.135)^{* * *}$ & $0.409(0.144)^{\star \star}$ & $0.052(0.126)$ \\
\hline Female Literacy & $1.132(0.083)^{\star * *}$ & $0.950(0.091)^{\star * \star}$ & $1.179(0.077)^{\star * *}$ & $1.132(0.083)^{\star * *}$ & $1.001(0.069)^{\star * *}$ & $0.282(0.091)^{\star *}$ \\
\hline Constant & $-5.515(8.658)$ & $10.328(9.456)$ & $-12.796(7.693)$ & -8.667 (7.972) & 3.952039 (7.127) & - \\
\hline Prob $>$ F-stat & 0.000 & 0.000 & 0.000 & 0.000 & 0.0000 & 0.000 \\
\hline Obs & 320 & 320 & 320 & 320 & 320 & 320 \\
\hline $\mathrm{R}^{2}$ & 0.912 & 0.982 & 0.666 & 0.660 & 0.908 & 0.953 \\
\hline
\end{tabular}

Note: Standard errors are reported in parenthesis, ${ }^{* *}$ denotes significance at the $5 \%$ level, ${ }^{* * *}$ denotes significance at the $1 \%$ level, $\mathrm{SBA}=$ skilled birth attendance, OOP=stands for out-of-pocket expenditure, GDP=stands for gross domestic product, Prob>F-stat stands for the probability associated with F-statistic, Obs stands for the number of observations and $\mathrm{R}^{2}$ stands for the coefficient of determination.

Table 2 Estimated impact of out-of-pocket expenditure on maternal mortality

\begin{tabular}{|c|c|c|c|c|c|c|}
\hline Variables & $\begin{array}{l}\text { Ordinary least } \\
\text { squares }\end{array}$ & $\begin{array}{l}\text { Prais-Winsten } \\
\text { regression }\end{array}$ & $\begin{array}{l}\text { Random effects } \\
\text { model }\end{array}$ & $\begin{array}{l}\text { Fixed effects } \\
\text { model }\end{array}$ & $\begin{array}{l}\text { Generalized } \\
\text { least squares }\end{array}$ & $\begin{array}{l}\text { Bias-corrected } \\
\text { least squares } \\
\text { dummy variable }\end{array}$ \\
\hline MMR & - & - & - & - & - & $0.969(0.035)^{\star \star *}$ \\
\hline OOP & $0.540(0.168)^{\star * *}$ & $0.446(0.128)^{\star * *}$ & $0.519(0.166)^{* *}$ & $0.540(0.168)^{\star * *}$ & $0.289(0.058)^{\star \star \star}$ & $-0.577(0.101)$ \\
\hline GDP & $-0.197(0.268)$ & $-0.104(0.114)$ & $-0.192(0.267)$ & $-0.197(0.268)$ & $-0.091(0.052)$ & $-0.206(0.146)$ \\
\hline Remittances & $0.153(0.472)$ & $0.291(0.556)$ & $0.168(0.463)$ & $0.153(0.472)$ & $0.135(0.300)$ & $0.541(0.279)$ \\
\hline Female literacy & $-2.860(0.290)^{\star \star \star}$ & $-1.408(0.326)^{\star \star \star}$ & $-2.867(0.286)^{\star \star \star}$ & $-2.860(0.290)^{\star \star \star}$ & $-1.172(0.173)^{\star \star \star}$ & $-0.237(0.213)$ \\
\hline Constant & $314.965(30.152)^{\star * *}$ & $\begin{array}{l}178.584 \\
(32.391)^{\star \star \star}\end{array}$ & $\begin{array}{l}338.437 \\
(31.697)^{\star \star *}\end{array}$ & $\begin{array}{l}337.185 \\
(27.763)^{\star \star \star}\end{array}$ & $\begin{array}{l}160.912 \\
(16.990)^{\star * *}\end{array}$ & - \\
\hline Prob $>F-$-stat & 0.000 & 0.000 & 0.000 & 0.000 & 0.000 & 0.000 \\
\hline Obs & 320 & 320 & 320 & 320 & 320 & 320 \\
\hline$R^{2}$ & 0.957 & 0.945 & 0.109 & 0.108 & 0.790 & 0.992 \\
\hline
\end{tabular}

Note: Standard errors are reported in parenthesis, ${ }^{* *}$ denotes significance at the $5 \%$ level, ${ }^{* * *}$ denotes significance at the $1 \%$ level, MMR= maternal mortality ratio, OOP=stands for out-of-pocket expenditure, GDP=stands for gross domestic product, Prob>F-stat stands for the probability associated with $\mathrm{F}$-statistic, Obs=stands for the number of observations and $\mathrm{R}^{2}$ stands for the coefficient of determination. 


\section{Discussion}

The results show that the trends of births by skilled birth attendants and the maternal mortality ratio between 2000 and 2015 were improved in Central and Latin American countries, but an increase in OOP health expenditure was associated with a significant decrease in skilled birth attendance. World Bank data show that in 2015 the population of Latin America and the Caribbean was estimated at 632 million, while the annual birth rate was estimated to be 17.1 births per 1,000 people. During that year, about $93.9 \%$ of births were attended by skilled healthcare staff on average. However, when we consider the estimate of the 10.8 million newborn babies recorded in the region, it could be that about 650,000 babies were delivered without the assistance of any qualified healthcare staff. Such a figure puts things into perspective and shows that even though it is not the only explanatory factor of skilled birth attendance, OOP health expenditure could affect the health outcome of thousands of mothers and babies. These findings are in agreement with the previous studies that highlighted the catastrophic effect of OOP payments on health in general. ${ }^{2-5}$

A surge in OOP healthcare expenditure leads to a significant increase in the maternal mortality ratio, as shown in our analysis. Indeed, pregnant women who cannot afford the medical expenses associated with their condition have a significantly increased probability of losing their lives during pregnancy or delivery. Our findings showed that a $1.0 \%$ increase in OOP healthcare expenditure could threaten the lives of 290 out of 100,000 mothers, which is a meaningful call for attention and also raises worries about the future health outcomes of the corresponding babies. When healthcare expenses become too high for low- and middle-income households, they usually shy away from hospitals, thus allowing pregnant women to deliver their babies without the assistance of any qualified healthcare personnel, exposing them to the risk of death and a vicious cycle.

Female literacy rates significantly increased skilled birth attendance and significantly decreased maternal mortality, indicating that education improves maternal health. Our findings were consistent with our initial assumption that education improves maternal health and could be explained by the fact that educated women are more aware of the dangers related to poor maternal health. Thus, notwithstanding the level of their income, these women are more likely to utilize healthcare facilities.

Concerning income, remittances were found to have a positive and significant effect on skilled birth attendance, while the effect of GDP was insignificant. Such findings reveal that in Central and Latin American countries, women rely more on money received from friends and family members living abroad for maternal health care. Furthermore, the effect of remittances was consistent with a study conducted by Massey et al. ${ }^{10}$ which determined that people living in this part of the world rely on remittances to support their consumption and investment needs.

Our study highlighted the effect of OOP payments on maternal health in Central and Latin American countries. More interventions of risk protection for poor maternal health outcomes are required. There are several studies which claim that health insurance is helpful for financial protection against impoverishing medical expenses and improves access to timely and quality medical care, ultimately leading to better health outcomes. ${ }^{1,13-17}$ Likewise, the health insurance policy (Seguro Popular) implemented in Mexico has proven to be effective and significant in protecting the people against catastrophic healthcare expenditures. ${ }^{4}$ The issues of health insurance or other methods of financial risk protection for healthcare services are important and need to be studied in Central and Latin American countries, as well as other continents. 


\section{Conclusion}

The trends of maternal health measured in births by skilled birth attendants and the maternal mortality ratios in Central and Latin America countries have been improving continuously. However, the evidence of this analysis shows that OOP expenditure is negatively and significantly associated with maternal health outcomes. In the context of each Central and Latin American country, the causes of OOP should be investigated and mitigated in order to improve maternal health outcomes.

\section{Conflict of interest}

The authors have no conflict of interest to declare.

\section{References}

1. Escobar ML, Griffin CC, Shaw RP. The impact of health insurance in low- and middle-income countries. Washington DC: Brookings Institution Press; 2010.

2. Mclntyre D, Thiede M, Dahlgren G, Whitehead M. What are the economic consequences for households of illness and paying for health care in low and middle income country contexts? Soc Sci Med 2006;62:859-62.

3. Mohanty S, Srivastava A. Out-of-pocket expenditure on institutional delivery in India. Health Policy Plan 2013;28:249-56.

4. Galarrago O, Sosa-Rubi S, Salinas-Rodriguez A. Health insurance for the poor: impact on catastrophic and out-ofpocket health expenditures in Mexico. Eur J Health Econ 2010; 11:437-42.

5. Frenk J, Gonzalez-Pier E, Gomez-Dantes O. Comprehensive reform to improve health system performance in Mexico. Lancet 2006;368:1524-34

6. Leive $\mathrm{A}, \mathrm{Xu} \mathrm{K}$. Coping with out-of-pocket health payments: empirical evidence from 15 African countries. Bull WHO 2008; 86:849-60

7. Dammel W, Leemput L, Por I, Hardeman W, Meessen B. Outof-pocket health expenditure and debt in poor households: evidence from Cambodia. Trop Med Int Health 2004;9:273-75.

8. Minh H, Phuong N, Saksena P, James C, Xu K. Financial burden of household out-of-pocket health expenditure in Viet Nam: findings from the national living standard survey 2002-2010. Soc Sci Med 2013;96:258-60.

9. Correa-Burrows P. Out-of-pocket health care spending by the chronically ill in Chile. Proc Econ Fin 2012;1:88-97.

10. Massey D, Arongo J, Hugo G, Kouaouci A, Pellegrino A, Taylor J. An evaluation of international migration theory: the North American case, Popul Dev Rev 1994;20:699-751.

11. Bruno G. Estimation and inference in dynamic unbalanced panel data models with a small number of individual. Stata J 2005;5:473-500.

12. Anderson R, Hsiao C. Formulation and estimation of dynamic models using panel data. J Econ 1982;18:47-82.

13. Bovbjerg RR, Hadley J. Why health insurance is important. DC-SPG 2007;1-3.

14. Bernstein J, Chollet D, Peterson S. How does insurance coverage improve health outcomes?. Math Policy Res 2010;1-5.

15. OECD. Universal health coverage and health outcomes. Final report 2016 [monograph on the internet]. Paris: OECD [cited 2016 Jul 22]. Available from: https://www.oecd.org/els/ health-systems/Nniversal-Health-Coverage-and-HealthOutcomes-OECD-G7-Health-Ministerial-2016.pdf

16. Bonfrer I, Breebaart L, Van de Poel E. The effects of Ghana's national health insurance scheme on maternal and infant health care utilization. Plos One 2016;11:e0165623.

17. Sommers BD, Gawande AA, Baicker K. Health insurance coverage and health -what the recent evidence tells us. New Eng J Med 2017;377:586-93. 